\title{
ÇANAKKALE ZAFERİ VE ATATÜRK
}

\author{
Dr. Ismet GÖRGÜL Ü
}

\section{ÇANAKKALE ZAFERI'NİN ÖNEMI}

Köklü Türk tarihinin altın sayfalarından biri olan Çanakkale Zaferi, her yıl büyük coşku ile kutlanır.

Bu zaferi anma günlerinde, Türk'üm diyen herkesin duyması gereken heyecan, coşku, gurur çok büyüktür.

Neden heyecan ve gurur duyuyoruz? Neden aradan 81 yll geçmesine rağmen bir muharebedeki zaferimizi bu denli önemle kutluyoruz? Dikkat edilirse, bize bugünkü vatanımızı ve devletimizi sağlayan Kurtuluş Sava\$̧1 Muharebeleri'nden sadece Başkomutan Meydan Muharebesi'ni ülke çapında, programlı törenlerle kutluyoruz. 1 nci İnönü ve 2 nci İnönü Zaferleri ile Sakarya Meydan Muharebesi'ni daha yöresel olarak kutlamaktayız. Sakarya Zaferi küçük bir zafer midir? Kesinlikle hayır. Türk tarihindeki geriye gidişin, batılı devletlerin biz Türk'leri önce Avrupa topraklarından, sonra Anadolu'dan atma çabalarının durdurulduğu bir muharebedir. Türk'ün tekrar batıya doğru ilerlemesini sağlayan bir zaferdir. İşte bütün bunlara rağmen Çanakkale Zaferi ön planda olagelmiştir.

Bu yazıda bunun nedeni üzerinde duracağız. Çünkü neyi, neden yaptığımızı, anlayarak, bilerek yapmalıyız.

Bu zafer Gelibolu Yarımadası üzerinde kazanıldı. O dönemdeki yani Birinci Dünya Harbi ł̧̧̧indeki düşmanlanımı İngiltere ve Fransa, Gelibolu Yarımadası'nı ele geçirerek Çanakkale Boğazı'nı açmak ve devamında da başkent İstanbul'u işgal etmek niyetiyle bu harekata başladılar. Böylece Türk'lerin Avrupa ile bağlantılarını da tamamen kesmiş olacaklardı. Fakat Gelibolu Yarımadası'nın bilindiği gibi bizim tarihimizde ayrıcalıklı bir yeri vardır. Bizim Avrupa'ya geçişimizdeki ilk bölgedir. Avrupa Kıtası'nda sahip olduğumuz ilk topraktır. Avrupa'ya attığımız ilk adımdır. 1354 yılında Gazi Süleyman Paşa tarafından Türk topraklarına katılmıştır. İşte böyle bir vatan parçasının çiğnetilmemiş olması ile Çanakkale Zaferi önemlidir. 
Çanakkale Zaferi'nden bir yıl önce Türk Ordusu, tarihinin en büyük hezimetini yaşamışır. Balkan Harbi, Balkan Faciası, bu mağlubiyet sonucunda; üç hafta içerisinde bugünkü topraklarımızın 1/5'inden daha fazla toprak, $167.000 \mathrm{~km}^{2}, 33$ vilayet, 158 ilçe, 6.5 milyon nüfus, bir başka ifadeyle Meriç Nehri'ne kadar Avrupa'daki toprakların tamamı kaybedilmiş ve ordu da elden çıkmıştı. İşte bu büyük darbeden sonra Türk Ordusu gerçek anlamıyla ordu olabilmek için büyük bir çabaya girişti. Bir yılık sürede, yüzüne sürülen kara lekeyi silecek duruma ve Çanakkale Zaferi'ni kazanacak güce erişti. Kazandığı zaferle Türk'ün gerçek kudret ve kabiliyetini ortaya koydu. Tarihindeki Türk'ün yaşadığını, Türk Milleti'nin cevherini, bütün Dünya'ya bir kere daha gösterdi. işte Çanakkale Zaferi bunun için önemlidir.

Çanakkale Zaferi, bize en pahalıya mal olan zaferimizdir. Karşılığında, en çok insan kaybina maruz kaldığımız bir zaferdir. Bu zafer için hemen hemen her evden bir iki şehit verilmiştir. Türk Milleti, binlerce aydınını, okumuşunu bu savaşta yitirmiştir. Anadolu'dan ve özellikle İstanbul'dan akın akın gönüllü öğretmen, mülkiyeli, tıbbıyeli öğrenciler, Türk Ocakları'nda yetişmiş okur-yazarlar, aydınlar bu savaşa katılmışlar ve can vermişlerdir. Bu savaşa toplam 400.000 Türk katılmış ve bunun 250.000 'i zayi olmuştur. Üç yıl süren Kurtuluş Savaşı'nda en güçlü olduğumuz dönem olan Büyük Taarruz'da ancak 100.000 kişilik bir ordu yapabildiğimiz ve bütün Kurtuluş Savaşı boyunca 40.000 kişilik zayiat verdiğimiz hatırlanırsa, Çanakkale Zaferi'nin bedeli daha iyi anlaşılır. Birisinde bir zafer kazandık, birisinde ise vatanı kurtardık. Sonuç olarak Çanakkale'de bir nesli kaybettik, Gelibolu'ya bir nesli gömdük. Işte Çanakkale Zaferi bunun için önemlidir.

Çanakkale Zaferi dünyaya, Türk'ün tükendiği sanılan gücünün henüz tükenmediğini, artık tarihi misyonunu tamamladığını sandıkları Türk'ün, şartlar ne kadar zor olursa olsun, daha çok şeyler başarabilecek güç ve inanca sahip olduğunu göstermiştir. Karşımızdakiler bir devletin çöküşü ile milletin inanç ve gücünün çöküşünün farklı şeyler olduğunu burada anlamışlardır. Türk'ün devleti çökebilir ama kendisi çökmez. Dünya sahnesindeki rolünü bırakmaz. İşte Çanakkale Zaferi bunun için önemlidir.

Çanakkale'de karşımıza o dönemin süper güçleri olan İngiltere ve Fransa vardı. İngiltere, yedi denizin hakimi, toprakları üzerinde güneş batmayan bir imparotorluk ve namağlup bir devlet idi. Bununla da aşırı gurura kapılmıştı. Her iki devlet, sömürgelerindeki kaynaklarını da bu savaş için seferber etmiş ve 600.000 asker kullanmıştı. Başlangiçta zaferden hiç kuşku duymayan bu iki dev, Türk'ün azmi, vatanı için vatanından başka herşeyini feda eden anlayışı karşısında, mağlubiyeti kabul etmek zorunda kaldı. 252.000 zayiat vererek Gelibolu Yarımadası'ndan kaçtı. $\mathrm{Bu}$ kaçış İngiliz İmparatorluğu için geriye gidişin başlangıcı olmuştur. Dünyadaki prestiji sarsılmıştır. Asya ve Afrika' da, çok geniş bir alandaki 
sömürgelerinde yaşayan müslüman milletlere, bu zaferle istiklal ve hürriyet tohumları atılmıştır. Bu da ileride, dünya siyasi haritasının şeklini degiștirecek gelişmelere sebep olmuştur. İngilizlerin gururunu kırmayı, İngiltere ve Fransa gibi iki büyük devleti tek başına, müttefiki Almanya'dan yardım almadan yenmeyi başaran, arkasından da dünya siyạsi haritasının değişmesine sebep olan Türk Milleti'dir. İşte Çanakkale Zaferi bunun için önemlidir.

Çanakkale Zaferi, ümmetçiliği iflas ettirmiş, islam birliği panislamizm fikrini çökertmiş, söndürmüş̧tür. Yerine, Türk Milliyetçiliği fikrini alevlendirmiştir. Bunun uygulanabilir olduğunu, gerçek olduğunu kanıtlamıştır. O dönemde; bugunkü Irak, Suriye, Suudi Arabistan, Birleşik Arap Emirlikleri topraklarımız içinde, Libya'da kontrolumuz altında idi. Harp başlayınca bilindiği gibi Cihadi Mukaddes ilan edilir, ancak bunun olumlu hiçbir etkisi görülmez. Türk unsurunun disındaki Osmanlı tebası olan diğer müslüman unsurlarına İngiliz altını ve Ingiliz vaatleri, Osmanlı'nın ilan ettiği Mukaddes Cihat'tan daha sıcak gelir ve Osmanlı Türk'ünü arkadan vururlar. Çanakkale Muharebeleri sırasında da daha acısı yaşanır. İngiliz ve Fransız'lar sömürgeleri olan müslüman ülkelerden, Hindistan'dan yani bugunkü Pakistan'dan, Fas, Tunus ve Misır'dan, Senegal ve diğerlerinden önemli sayıda müslüman asker getirirler ve bunlan Türk'lere karşı savaştırırlar. Hatta bizim cephelerdeki Mehmetçikleri etkilemek için yüksek seslerle ezan ve Kuran-1 Kerim bile okuturlar. İşte bu tablo gerçeği görmemizi sağlar. $\mathrm{O}$ dönemde oldukça ağırlıklı bir görüş̧ olan, hatta devletin politikası olan İslam Birliği düşüncesinin, bir hayal olduğunu; ümmetçilik yerine milliyetçiliğin esas olması gerektiğini gösterir. Böylece gerek Osmanlı Devleti'nin son dönemine, gerekse T.C. Devleti'nin milli politikasına yön vermiş olur. Ayrıca bu zafer bugün dahi bu hayalin peşinde koşanlara, İslam Birliği'ni ideoloji olarak benimseyenlere, millet gerçeğini inkar edip milleti ümmetleştirmeye çalışanlara, düşüncelerinin çürüklüğünü gösteren tarihi bir ispattır. İşte Çanakkale Zaferi bunun için önemlidir.

Bu zaferin belki de bizim için en önemli yanı Milli Mücadele ruhunun ilk meşalelerinin burada yakılmış ve T.C.' nin ilk temel taşlarının bu mücadeleler sırasında atılmış olması ile Türk Milletine Mustafa Kemal Atatürk'ü kazandırmış olmasıdır.

Atatürk'ün üstün özellikleri, Bu muharebeler sırasında su yüzüne çıkmış ve milletin dikkatini çekmiştir. Kazandığı başarılardan dolayı, daha muharebeler devam ederken "Istanbul'u kurtaran kahraman", "payitaht kurtaran kahraman" ünvanı ile anılmaya başlar, o dönemin en önemli dergisi olan Harp Mecmuası'nda boy boy resimleri çıkar. Halkın ağzında bir efsanevi kahraman olur. Yakup Kadri, "Atatürk" isimli eserinde, halktan duyduklarını şöyle yazar:

"Bu genç kumandan, yanında bir avuç süngülü askerle, yerden, gökten, denizden gelen sürekli bir gülle, kurşun ve şarapnel sağanağının orta- 
sında durmadan ileriye doğru atılıyor ve kollarıyla, kızgın boyunlarından yakalayıp denize yuvarlayacakmış gibi düşmanın sıra sıra toplan üstüne saldırıyor. Bu insan, ateşte yanmıyordu. vücuduna kurşun işlemiyordu ve zırhlıların (savaş gemilerinin) attığı gülleler başının üstünden münisleşmiş, yırtıcı kuşlar gibi geçip gidiyordu".

$\mathrm{Bu}$ anlatım Atatürk'ün tam bir masal kahramanı gibi algılandığını gösteriyor ki, o neslin de bir beklenti içinde olduğunu yine Yakup Kadri kitabının başlangıcında şöyle ifade eder.

"Bizim ilk gençlik yıllarımız bir milli kahramana hasretle geçti" der.

İte Çanakkale Muharebeleri ile beklenilen kahraman çıkmıştır. Mustafa Kemal, bu zaferden kazandığı prestij ile milli mücadeleye atılmış; askerlikten istifa etmesine ve hakkında idam fermanı çıkartılmış bir sivil olmasına rağmen kendisine bağlı ve kendisini bir lider olarak benimsemiş bir ordu ile millet bulmuştur. Bu ortam ise Türk'ün kurtuluşunu sağlamış ve tarih sahnesinden silinmesini önlemiştir. İşte Çanakkale Zaferi bunun için önemlidir.

\section{ATATÜRK’ÜN ÇANAKKALE ZAFERI'NDEKİ YERİ}

Peki, Atatürk ne yapmıştır da efsanevi kahraman, milli kahraman olarak Türk Milleti'nin gönlüne girmiştir? Nasıl kahraman olmuştur? Çanakkale Muharebeleri'ne; 20 tümen, 39 tümen komutanı; 10 kolordu, 52 alay, 104 alay komutanı; 18 kolordu komutanı; iki ordu, iki ordu komutanı; binlerce subay, yüzbinlerce ecdat katılmıştır. Bu büyük zaferde şimdi rahmet ve şükranla andığımız, pek çok büyüğümüzün payı vardır. Can vererek bu zaferi kazanmıslardır.

Durum böyleyken nasıl oluyor da Atatürk ön plana çıkıyor? Çanakkale Zaferi O'nun yüce adıyla özdeşleşiyor? Çanakkale denilince akla Mustafa Kemal geliyor? Yoksa Milli Mücadele'yi zaferle sonuçlandırdığı, vatanı düşman işgalinden kurtardığı için mi sonradan zafer üzerine fatura edilmiştir?

\section{Şimdi biraz bunlar üzerinde duralım:}

Yüce Atatürk'ün Çanakkale Zaferi ile özdeşleşmesi sonradan değildir. Daha muharebeler devam ederken ismi parlamaya başlar, Çanakkale Cephesinin en önemli ve güven duyulan komutanlarından biri olur. Bununla ilgili birkaç kaynaktan duruma bakalım.

Birinci Dünya Harbi sırasında asker-sivil işbirliği ile çıkarılan Harp Mecmuası isimli bir dergi mevcuttur. Bu derginin 1915 yılına ait 2 ve 4 ncü sayılarında Alb. Mustafa Kemal'e geniş yer verilir. 4 ncü sayısında Çanakkale Kireç Tepe'de mermi kovanlarından yapılmış bin anıtın önünde çekilmiş fotoğrafı, tam sayfa olarak yayınlanır ve altına şunlar yazılır: 
Büyüklüğ̈̈ne söz bulunamayan

Bir levha-i Şehamet (Akılla yaratılan bir yiğitlik levhası)

Bu cümle çok önemlidir. Daha o dönemde, yüce Atatürk'ün kahramanlığı, yiğitliği ve bunan akılla yaratıldığı ile büyüklüğü teslim edilmiş ve bu büyüiklüğünü ifade için söz bulunamadığından yakınılmıștır. Bu sözler herkes için söylenmemiştir ve özellikle henüz albay rütbesindeki bir komutan için bu sözler çok büyüktür. Ama öyle değerlendirilmiş ve böyle yazılmıştır.

2 nci sayısında da Birinci Dünya Harbi'nin genel değerlendirmesi yapilırken yine Atatürk'e yer verilmiş, bir resmi konmuştur.

Atatürk'ün kazandığı bu haklı ün, Başkomutanlıkta da etkisini gösterir. Daha muharebelerin ilk iki ayı içerisinde başarılarından dolayı rütbesi albaylığa yüksektilir ve toplam 3 madalya ve 3 nişan verilir. Ayrıca kendisine iki önemli görev için tayin teklifi yapılır. İlki, daha kendisi Tümen Komutanı iken Temmuz 1915 ortasinda, Trablusgarb'e ordu komutanı yetkisiyle ve Tuğgeneral (Mirliva) rütbesi ile gitmek arzusunda olup olmadığı sorulur. Ikincisi ise Anafartalar Grup Komutanı iken 1915 Ekim ayı başında, Irak Ordusu Komutanlığına tayin teklifidir.

Bu olaylar devleti yönetenlerin Atatürk'e bakış açısını sergilemektedir. Yani daha muharebeler sırasında, henüz zafere erişilmeden Anafartalar Kahramanı Mustafa Kemał tanınmış ve hakkı teslim edilmiştir.

Zaferden sonra ise Mustafa Kemal ismi, efsanevi bir kimlik kazanır. Artık istanbul'u kurtaran kahraman ünvanı ile anılır. Gazeteciler, yazarlar kendisiyle mülakat yaparlar.

Halkın en büyük arzusu ise kendisini görmektir. 1916'nın Ocak ayında 16 ncı Kolordu Komutanı olarak Edirne'ye girişinde halk sokaklara dökülür.

Atatürk'ün Çanakkale'de ve sonrasında Kurmay Başkanlığı'nı yapmış olan Orgeneral İzzettin Çalışlar, günlüğ̈̈nde bu karşılanışı şöyle anlatır:

Kanunusani 15.1331 (28 Ocak 1916)

... Yollar hıncahınç ahaliyle dolmuş, bütün mektepler karşılama için yerlerini almıştı. Şehir saray gibi donanmış, peş peşe zafer takları yapılmıştı. "Yaşasın Arıburnu ve Anafartalar Kahramanı Mustafa Kemal Bey" yazılı levhalar asılmıştı... Edirne eşrafı, vilayet erkanı, konsoloslar hep oradaydılar... Bütün şehir, heyecan ve coşkulu sevinçle karşıladı. Çiçekler, buketler takdim ettilir. Alkışlar, her türlü nümayişler, tezahurat, her türlü tasavvurun üstündeydi..." 
Görüldüğü gibi Atatürk'ün şöhreti, halkın kendisine layık gördüğü ünvanlar, kendisine duyulan hayranlık o günlerde ortaya çıkmıştır,. Sonradan yakıştırma değildir. Tarihte herhalde bir şehir halkı, hiçbir albayı bu şekilde karşılamamıştır. Fakat Albay Mustafa Kemal'i karşılamıştır. Albay Mustafa Kemal ne Edirne'nin fatihidir, ne de Edirne'yi düşmandan kurtarmıştır. Edirne'de çalışmamış, fiziken Edirne'liler tarafından tanınmıyordu. Bunlara rağmen karşılanışın bir Fatih'e yaraşır biçimde olduğunu anlıyoruz. Sebep, Çanakkale'de yaptıklarıdır. Yaptıkları ile kazanılan zaferdir. Türk Milletine, ikiyüz yıldır hasret kaldığı zafer coşkusunu tekrar tattırmasidır. Bir büyük zafer armağan etmesidir.

Yüce Atatürk'ün Çanakkale Muharebeleri'ndeki yerini ve zaferdeki payını; bu muharebelere katılmış $\mathrm{H}$. Cemal adlı bir subay, 1915 yılında yazdığ 1 "Ulu Cenk" isimli Çanakkale Muharebeleri'ni anlatan kitabında; Atatürk için ayrı başlık açıyor ve O'nun farklılığını anlatıyor. Başlık ilginçtir.

"Anafartalar Muharebeleri

Komutanı Mustafa Kemal Bey

Yarınki Harbiye Nazırımız"

Bu başlığın altında yazar, kanaatini bir sonuç cümlesi ile ifade ediyor ve konuya giriş yapıyor:

"Çanakkale'ye bir zafer heykeli dikmek şerefi ile Türkler şeref kazanacaklarsa o heykelin, Çanakkale'yi kurtaran Mustafa Kemal Bey olması lazımdır. Başkası olamaz. Bu hak kimseye verilemez."

Bu satırların 1915 'te yazıldığını tekrar hatırlatalım ve konunun devamından birkaç cümle daha aktaralım:

"Türk askerini, yalnız bu komutan, hiçbir vakit lüzumsuz yere harcamiyor. Gerek subaylar, gerek erler Arıburnu siperlerinden söz ederken Mustafa Kemal'in adını hürmetle anıorlar..."

"Bu zafer hatırası şerefine, bundan sonra Akdeniz'in gölgeli dalgala$\mathrm{n}$ arasında uzak-yakın memleketlerden gelen bir gemi, boğazların, bu hilafetin anahtarı üzerinde sallanan Türk Bayrağı'nı görünce selam verecek, orada daima Türk askerini ve onun kahraman komutanı Mustafa Kemal'i hatırlayacaktır.

Mustafa Kemal için bugün Almanlar, gazeteleriyle bir övgü sütunu yazarlarsa, yarın dünya, bu komutanın zafer destanlarını söyleyecektir.

Böyle komutanlarımızı takdir etmek, onların adına heykel dikmek, yaşama hakkımızdaki nasibimizi müjdeler." 
Bu cümleler, O'nun sayesinde bir vatana, bir millete sahip olduğunu, O'nun sayesinde hayatiyet kazandığını, insan gibi yaşadığını unutanlara ithaf olunur.

$\mathrm{Bu}$ açıklamalardan şu sonucu çıkanyoruz. Yüce Atatürk'ün Çanakkale Zaferi'ndaki payı çok büyüktür. Bu zaferin baş mimarı O'dur. Bu durum daha o zamanlar, kendisine teslim edilmiştir.

Bunlar, yazılanlar açısından konuyu ispatlama niteliğindeydi. Aslında yeni birşey ileri sürmedik. $O$ günlerde bilineni kendi yaklaşımımız ve inceleme sonucu bulduklarımızla tekrarlamış olduk.

Şimdi de Yüce Atatürk'ün neler yaparak "Anafartalar Kahramanı" "İstanbul'u Kurtaran Kahraman" ünvanlarını aldığını kısaca açıklayalım. Bu konu aslında bir kitap konusudur. Ancak biz burada sadece ana hatları ile birkaç nokta üzerinde duracağız.

Yüce Atatürk beş defa İstanbul'u kurtarmıştır. Yani Çanakkale'de mağlubiyeti önlemiştir. Çanakkale'de mağlubiyet demek İstanbul'un düşmesi demektir. Onun için İstanbul'u kurtarmıştır denilir. Onun için payitahtı yani İstanbul'u kurtaran kahraman denmiştir.

İlki, muharabelerin ilk günü olan 25 Nisan 1915 'tedir. Düşman Arıburnu kıyısına asker çıkarmışır. Kıyıda çok zayıf kuvvetimiz vardır. Düşmanı durduramaz. Düşman Conkbayırı'na doğru ilerlemektedir. Conkbayırı düşman eline geçtiği takdirde Çanakkale'de savunma imkansiz hale gelir, buradaki kuvvetlerimiz imha olur; sonucunda İstanbul'a hem deniz, hem karayolu açılır ve İstanbul düşer. İşte böyle hayati dakikalar yaşandığında Yb. Mustafa Kemal, Arıburnu'na çıkan düşmana taarruz edilmesi gerektiğini düşünür ve Kolordu Komutanından müsaade ister. Kolordu Komutanı bu durumda kendisi karar veremez. Çünkü Mustafa Kemal'in Tümeni ordu ihtiyatıdır. Kullanılması için Ordu Komutanından emir alınması gereklidir. Ayrıca düşmanın üç ayrı yere birden çıktığı öğrenilmiştir. Mustafa Kemal'in 19 ncu Tümeni Arıburnu'nda kullanıldığı taktirde diğer bölgelerde meydana gelebilecek tehlikelere karşı elde kuvvet kalmayacaktır. Ordu Komutanının da Saros Körfezi bölgesine gittiği öğrenilmiştir. Ordu Komutanı gittiğine göre belki bu bölgeye bir çıkarma başlamıştır. Bununla ilgili bilgi mevcut değildir. İşte bu nedenlerle Kolordu Komutanı karar veremez. Ordu Komutanına danışalım der. Ancak telefonla temas kurulamaz. Kolordu Komutanı görüşmek üzere Saros Bölgesine gider. $40 \mathrm{~km}$.lik mesafe, en azından iki saat sürecektir. Yani en erken öğleden sonra dönebilecektir. Fakat düşman onun dönmesini beklemeyecektir. İşte bu durumda Yb. Mustafa Kemal, Çanakkale Muharebeleri'nin kaderini değiştiren bir iş yapar. Durumun öneminden dolayı, ordudan gelecek emri beklemeden düşmana taarruza karar verir ve taarruz eder. Sorumluluğu üzerine almıştır. Büyük riske girmiştir. Yaptiğı işten dolayı başına gelebilecekleri önemsemeden Çanakkale'nin kurtarılması için kendisini tehlikeye atmıştır. Vazifeyi herşeyden üstün 
tutmuştur. Kahramanlık işte budur. Harp Mecmuası kapağındaki resminin altına yazılan "Şahamet"; yani akılla yaratılan kahramanlık kavramı buradan itibaren başlar.

Yüce Atatürk, insiyatifeyle başlattığı bu taarruzla, tam düşmek üzereyken Conkbayırı'nı düşmandan kurtarır ve onu kıyıya kadar sürer. Böylece hayati tehlikeyi önler. Eğer bu taarruz gecikseydi, Canakkale Muharebeleri birinci gününde kaybedilirdi. Zaferimizle değil, Balkan Harbi gibi facia ile sonuçlanırdı. Bunu önleyen Atatürk'tür. Sadece bu kahramanlığı bile Ulu Cenk isimli kitapta yazılanlan hak ettirmektedir.

Burada şu akla gelebilir. "Başka bir subay olsaydı, o da hemen hemen aynı şeyi yapabilirdi.” Biz bu görüşte değiliz. Bunun en açık ispatı da muharebe sahasının Kolordu Komutanı olan Yanyalı Esat Paşa'dır. Atatürk kendisine taarruzu teklif ettiği halde taarruz emri verememiştir. Ordu Komutanının emrinin beklenmesini söylemiştir. Kaldı ki Yanyalı Esat Paşa sıradan bir paşa değildir. Balkan Harbinde, Yanya Savunması ile ün yapmış, ender başarılı komutanlardan birisidir. Harp sanatının ustasıdır ama tarruz emrini verememiş̧ir. Ayrica kaç subay, kolordu komutanının bu emrinden sonra kendiliğinden bu taarruzu yapabilir? İşte bu sorunun cevabi, akla gelen sorunun da cevabidır.

Yüce Atatürk, 25 Nisan'dan itibaren, sonuna kadar 8,5 ay süre ile bu muharebelerin en çetin görevlerini üstlenmiş, bütün faaliyetlerinde son derece başarılı olmus, verdiğimiz örnekteki gibi sayısız kahramanlıklar göstermiş̧ir. Bunlar üzerinde uzun uzadıya duramıyacağız. Sadece İstanbul'u kurtarmasını sağlayan diğer kahramanlıklarını kısaca açıklayacağız.

İstanbul'u ikinci kurtarı̧̧1 7 Ağustos günü olmuştur. 19 ncu Tümen Komutanı'dır. Arıburnu'nda cephenin bir bölümünü savunmaktadır. Cephesine yoğun şekilde düşman taarruz etmektedir. Düşmanın bir kolu da Conkbayırı'nı kuşatıcı şekilde ilerlemektedir. Burada 30-40 kişilik kuvvetimiz vardır ve gelen düşmanı durduramayacaktır. Ve burası Albay Mustafa Kemal'in bölgesi dışındadır, Bu bölge üzerinde hiçbir sorumluluğu yoktur. Buna rağmen ve kendi cephesine de yoğun şekilde taarruz edilmesine rağmen, elinde kalan son kuyvetinin tamamını (1,5 tabur kadar) Conkbayırı'na gönderir. Conkbayırı'nın düşmesini ikinci defa önler. Dolayısıyla İstanbul'u ikinci defa kurtarmış olur.

Üçüncü kurtarışı da 10 Ağustos günüdür.

8 Ağustos gecesi Anafartalar Grup Komutanı olur. 9 Ağustos günü Birinci Anafartalar Zaferi'ni kazanır. 10 Ağustos günü de düşmanın, hem bu mağlubuyetin acısını çıkarmak hem de kesin sonuca ulaşmak için büyük kuvvetleri ile Conkbayırı'na taarruz edeceğini değerlendirir. Düşmanın bu taarruzunu önlemek için, düşmandan önce Conkbayırı'ndan taarruz etmeye karar verir. Geceleyin Conkbayırı'na gelir. Burada önemli nokta; Conk'taki kuvvetlerimizin 10 Ağustos sabahı düşmanın yapacağı 
taarruza karşı koyamayacak şekilde zayıf olması, bu kuvvetlerle taarruza karar verilmesidir. Gece süresince başka yerden kuvvet getirmekte mümkün olmayacaktır. Yani bir yeri, bulunduğu yerde durarak koruyamayacak kuvvetlerle düşmana taarruz ederek, bu yeri savunmak düşünülmüştür. Isşte bu askeri dehadır. Akıldan doğan kahramanlıktır.

Yüce Atatürk, geceleyin Conk'a ulaştığında oradaki tümen komutanına taarruz emrini verir. Tümen komutanı ve kurmayı şaşırırlar ve hayrete düşerler ve Atatürk'e şöyle derler:

"İki günden beri devamlı surette taarrruz ettikleri halde başarilı olunamàdığını ve bu yüzden birliklerin büyük kayıp vermiş halde bulunduklarını, iş yapamayacak ve perişan durumda olduklarını, yeni bir taaarruza kalkışmanın neticesini vahim gördüklerini" ifade ederler.

Atatürk, Anafartalar Muharebatına Ait Tarihçe isimli kitabında bu değerlendirmeyi hesap olarak doğru ve mantıklı bulduğunu, reddi mümkün olmayan bir muhakeme olduğunu yazar ve şöyle devam eder:

"Bazı kanaatler vardır ki onların hesap ve mantıkla izahı pek güçtür. Özellikle muharebenin kanlı ve ateşle safhasındaki duyguların doğurduğu kanaatler....

Söylenenler gerçekten durumu ve kıtaların halini olduğu gibi tasvir ediyordu. Fakat bu değerlendirmeyi kararımı değiştirecek nitelikte bulmadım. Çünkü ben düşmanı şedit veya seri bir baskın ile mağlup edebileceğimize kanaat hasıl etmiştim. Bunun için çok kuvvetten ziyade, çok dikkatli ve fedakarane bir sevk ve idarenin maksadı temin edeceğine hükmetmiştim" der.

10 Ağustos sabahı gün doğmadan birliklerin en önüne geçer, bizzat kendi verdiği işaretle Mehmetçikleri hücuma kaldırır. Hem de nasıl? Tabanca ve tüfeklerdeki mermileri çıkarttırır, süngü taktırır, sadece süngü ile düşman üzerine saldırıyı başlatır. Sırp Sındığı gibi, henüz yığınlar halinde uykuda olan düşman, bu sessiz hücum karşısında neye uğradığını şaşırır, bozulur, dağılır ve kaçar. Çok kayıp verdirilir. Gün doğumu ile taarruza geçecek olan düşmanın, kaçtığı bölgelerde savunma gücü kalmaz.

Atatürk böylece Conkbayırı'nı dolayısıyla İstanbul'u şehameti ile, askeri dehası ile, olmazı olur ederek bir kere daha kurtarır. Sağ göğsünden bir şarapnel parçası ile vurulması ve cep saati sayesinde kurtulması bugünkü muharebede olur.

İstanbul'u diğer kurtarışlan ise 9 Ağustos'taki Birinci Anafartalar ve 21 Ağustos'taki İkinci Anafartalar Zaferi ile olmuştur. İkinci Anafartalr Muharebesi'ndeki şehametinden, yani akılla yaratılan kahramanlığından küçïk bir örnek verelim. 
Düşman 21 Ağustos günü 6 tümenle (yaklaşık 70 bin kişi) Anafartalar Ovası'nda taarruza başlar. Bizim, bunun karşısında iki tümenimiz (yaklaşık 18 bin kişi) vardır. Düşman donanmasının yoğun ateşi altında bu kuvvetlerle, bu büyük taarruzu durdurmak mümkün değildir. Bir tümenimizde oldukça geridedir. Yetişmesi çok gec olacaktır. Yetişene kadar düşman cepheyi yarabilir. İşte böyle çok kritik bir durum yaşanir. Bu tümenin gelişine kadar olan zamanın kazanılması gerekmektedir. Burada askeri deha kendini gösterir. elde bir süvari alayı vardır. Anafartalar Grup Komutanı Albay Mustafa Kemal, bu alayı savunan kuvvetlerimizin üzerinden aşırtarak, taarruz için ilerlemekte olan düşmanın üzerine saldırtır. Sonunda gerekli olan zaman kazanılır. Kuvvetlerimiz cepheye yetişir.

$\mathrm{Bu}$ uygulama bir yaratıcilık örneğidir, bir buluş̧ur, akılla yaratılan kahramanlıktır. Kurallarla, kalıplarla kendini bağlamamış bir beynin ürünüdür. Askeri tarihte bir süvari kıtasının, kendisinden mislilerce büyük, taarruz eden bir düşmanın üzerine atılması ya görülmemiştir, ya da çok nadirdir. Çünkü bu şekildeki bir saldırının ötesi yoktur, ölüme kucak açmadır, süvarilerin kendilerini feda etmeleridir. Anafartalar' da da öyle olmuştur. Karşılığında da üç-dört misli büyüklükteki düşman yenilmiştir.

Birkaç kritik örnekle ebedi Başkomutanımızın, ölümsüz yüce Önderimizin Çanakkale Zaferi'ndeki payını ortaya koymaya çalıştık. Tekrar ifade ediyoruz. Zaferdeki payı, yeri bu kadar değildir. Saatlerce üzerinde konuşulacak boyuttadır. Bu kadan bile gösteriyor ki Çanakkale Zaferi'nin mimar, kilit adamı Albay Mustafa Kemal'dir. Orada bulunması da Türk Milleti için bir şans olmuştur.

Yüce Atatürk; vatanı kurtarmamış, bağımsızlığımızı kazandırmamış, yeni çağdaş bir Türk Devleti kurmamıs, insanın insan gibi yaşamasını sağlayan bir sosyal düzen getirmemiş, Türk'ü ümmetten millete çevirmemiş, kadınları insan yapmamış, fikir özgürlüğünü, serbest girişim özgürlüğünü getirmemiş, yaşama standardımızı yükseltmemiş, beyinlerimizi, aile hayatımızı, sosyal, ekonomik ve siyasi hayatımızı çağdaşlaştırmamış olsaydı bile, bu büyük zaferdeki payı O'nu ölümsüz kılmaya, O'nun milli kahraman olarak yaşamasına yeterdir. Yeter ki bu duruma bakanlar Türk olsun, kaderini Türkiye Cumhuriyeti'ne bağlamıs olsun ve biraz da insan olsun. Biraz insan olunduğu takdirde bu hakkı teslim etmemek mümkün değildir. İnsanlık yönü olan düşmanlan dahi bu büyük insanı Çanakkale Muharebeleri'nde yaptıklarından dolayı takdir etmişler ve övmüşlerdir.

Hiçbir güç, hiçbir artniyetli, Türk'ü karanlığa çekmek isteyen hiçbir akım, yüce Atatürk'ü Türk'ün gönlünden, ruhundan, beyninden silemez, silemeyecektir; O'nun yolundan ayıramaz ve ayıramayacaktır. Yetişmiş ve yetişmekte olan Mustafa Kemallerin çokluğu bunun teminatıdır. 